\title{
Redefining risk research priorities for nanomaterials
}

\author{
Khara D. Grieger • Anders Baun • \\ Richard Owen
}

Received: 4 August 2009/Accepted: 4 December 2009/Published online: 24 December 2009

(C) Springer Science+Business Media B.V. 2009

\begin{abstract}
Chemical-based risk assessment underpins the current approach to responsible development of nanomaterials (NM). It is now recognised, however, that this process may take decades, leaving decision makers with little support in the near term. Despite this, current and near future research efforts are largely directed at establishing (eco)toxicological and exposure data for NM, and comparatively little research has been undertaken on tools or approaches that may facilitate near-term decisions, some of which we briefly outline in this analysis. We propose a reprioritisation of NM risk research efforts to redress this imbalance, including the development of more adaptive risk governance frameworks, alternative/complementary tools to risk assessment, and health and environment surveillance.
\end{abstract}

Keywords Nanomaterials · Nanotechnology · Research priorities - Risk assessment .

Risk governance $\cdot$ Societal implications

K. D. Grieger $(\bowtie) \cdot$ A. Baun

Department of Environmental Engineering, Technical University of Denmark, 2800 Kongens Lyngby, Denmark e-mail: kdg@env.dtu.dk

\section{A. Baun}

e-mail: anb@env.dtu.dk

\section{R. Owen}

Policy Studies Institute, 50 Hanson Street,

London W1W 6UP, UK

e-mail: owenr@westminster.ac.uk

\section{Introduction}

While global sales of nanoproducts are expected to reach $€ 450$ billion within the next year (Hanssen et al. 2008), scientists and regulators are still left with many questions as to whether nanomaterials (NM) pose a risk to human health or the environment. The risk assessment framework developed for chemicals remains the predominant decision support tool, underpinning regulations that cover $\mathrm{NM}$ or providing information to make the case for regulatory amendment (Rocks et al. 2008). This framework is well known to many, comprising hazard identification, hazard assessment and risk characterization (including considerations of exposure) (Rocks et al. 2008; EPA 2009; Owen et al. 2009b). Associated uncertainty in the process can be managed, for example by the application of safety factors (European Commission 2003; Owen et al. 2009b). While it is recognised that methodologies underpinning the conceptual risk assessment frameworks (e.g. EU Technical Guidance Document (TGD), Organisation for Economic Co-operation and Development (OECD) Test Guidelines) may not be entirely fit for purpose (e.g. Crane et al. 2008), the general consensus has been that in principle the chemical risk assessment framework is sound to use for NM with some modifications (European Commission 2008b; OECD 2008a; SCENIHR 2007, 2009).

Whereas, in principle, risk assessment is a sound approach, in practice, it is not an easy task to 
complete as there are some very significant challenges to first overcome (e.g. Maynard et al. 2006). It is now acknowledged that its completion will quite possibly take decades even for those NM that are currently on the market, let alone those that are emerging. Similar challenges have been faced for other chemicals (e.g. endocrine-disrupting chemicals, Sumpter and Johnson 2008). However, NM may represent an extreme case due to their diversity (e.g. particle sizes, functionalities) and range of applications (Owen and Handy 2007; RCEP 2008; Linkov et al. 2009a). While the question of identifying the most appropriate mechanism(s) to support timely decisions (e.g. interventions) in the face of little or no data is far from new (Collingridge 1980), it may be more challenging for NM and, at the same time, of utmost importance given the ubiquitous nature of nano-embedded consumer products and applications (Project on Emerging Nanotechnologies 2008). Some fundamental questions concerning whether NM risk research efforts have been directed in the most effective fields for timely decisions regarding environment, health and safety risks include: How do research efforts compare between the fields dedicated to using traditional risk assessment frameworks and alternative or complementary frameworks or tools for NM? Are programs that feed into chemical-based risk assessment made at the expense of research into tools that can support near-term decisions? What are the alternatives to traditional risk assessment currently available and what are their strengths and weaknesses? This analysis aims to address these critical questions, in addition to providing a snapshot of publications, projects and funding schemes made in these fields. We then propose some recommendations for future NM risk research schemes to help ensure the responsible innovation of NM as well as ultimately protect human and environmental health.

\section{Risk assessment as a decision support tool: challenges posed by nanomaterials}

Scientists, international organizations and regulatory agencies have been actively working towards developing risk assessment for NM in recent years (e.g. NNI 2008b; EPA 2009; OECD 2009d; SCENIHR 2007, 2009). In general, it has not yet been possible to complete individual NM risk assessments (SCENIHR
2009) due to extensive uncertainties and knowledge gaps within nearly all aspects of the risk assessment process (RCEP 2008; Grieger et al. 2009). Among other challenges, there is a distinct lack of quantitative exposure and hazard data for both humans and environmental species for many NM (Crane et al. 2008; Handy et al. 2008; SCENIHR 2009; Wiesner et al. 2009). In addition, a number of key methodological concerns have been raised, including uncertainty in applying standardized test methods developed for chemicals to NM (e.g. to quantify hazards including sample preparation for (eco)toxicity studies, characterisation of $\mathrm{NM}$ in test systems, dosimetry and reporting metrics) (Crane et al. 2008; Powell et al. 2008; Shatkin 2008). Furthermore, there are also difficulties in detecting and quantifying NM in complex environmental matrices (Owen and Handy 2007; Hassellov et al. 2008).

Based upon a reflection of these challenges and in response to calls for more research (e.g. Maynard et al. 2006), increased efforts regarding these have been underway. For example, scientists and organisations have been actively generating and analysing data for effects and exposure assessments as well as reviewing risk assessment methodologies for their appropriateness for NM. Academics and scientists in government and regulatory agencies all play a role in these developments, as well as industry, for example under chemicals legislation in relation to NM (e.g. Registration, Evaluation, Authorisation and Restriction of Chemical substances, REACH) (European Commission 2008b).

In the EU, the European Commission's Scientific Committee on Emerging and Newly Identified Health Risks (SCENIHR) has recently reviewed the available data for risk assessment of NM (SCENIHR 2009). They conclude that the risk assessment framework seems applicable to NM although they acknowledge and describe many of its limitations, stating that the risk assessment process is still under development. Others such as the European Food Safety Authority have recently published similar conclusions, stating that although there are some major (e.g. methodological) challenges, current risk assessment methodologies are expected to be applicable for NM in food and feed applications in principle, and assessments should be undertaken on a case-by-case basis (European Food Safety Authority 2009). 
The challenges for risk assessment posed by NM are reflected by a significant program of work at the Organisation for Economic Co-operation and Development's working party on (manufactured) NM (WPMN). An array of projects are being directed, including the development of a NM risk research database (OECD 2009d), analysis of test methods (which underpin chemicals risk assessment) as applied to NM and a sponsorship program that will acquire risk assessment data for $14 \mathrm{NM}$ of current relevance (OECD 2008b). Further study has also been undertaken to prioritize research needs to close the known knowledge gaps as quickly as possible, supporting the performance of risk assessments often in the context of current regulatory testing requirements (DEFRA 2006, 2007; Maynard et al. 2006; ICON 2008; NNI 2008b; Elder et al. 2009; SCENIHR 2009).

On the whole, a consensus is beginning to emerge: risk assessment frameworks for chemicals should be appropriate for NM, but they most likely need some methodological modifications. Exactly what modifications are needed is not consistently made clear, and how long it will take to make these modifications is also not often stated.

Despite these serious technical challenges that risk assessors face, most knowledge gaps are expected to be reduced in due course because of their epistemic nature (RCEP 2008; Grieger et al. 2009). It is anticipated that eventually standardized testing methodologies and analytical tools will be developed alongside full NM characterization and dose-response data (ISO 2008a, b; OECD 2008a, b). History has shown many examples in which regulatory test methods were developed and applied (Baun and Hansen 2008; OECD 2009a, b) in response to new knowledge (e.g. endocrine-disrupting chemicals, Sumpter and Johnson 2008), and later test methods were developed (OECD 2009a, b). In fact, a recent review of the applicability of OECD test guidelines for NM (OECD 2009e) shows this process in action: some test guidelines for NM physical chemical properties appear to be adequate for NM (e.g. TG 102, 109, 113, 116), some may be applicable in some cases or for some NM (e.g. TG 101, 105, 106, etc.), while other guidelines are considered inadequate (e.g. TG 103, 114).

However, how long will this process take especially given the diversity of NM and applications? A recent analysis estimates that testing existing nanoparticles in the USA alone will cost between $\$ 249$ million and $\$ 1.18$ billion and take $34-53$ years for completion (Choi et al. 2009). Earlier analyses also estimated, at least, a decade for the acquisition of some critical knowledge within the field (Maynard et al. 2006). Given this, some have suggested that more rapidly deployable decision-support frameworks and/or tools need to be applied now (Hansen 2009; Linkov et al. 2007, 2009a; Mantovani et al. 2009; Metcalfe et al. 2009). In addition, others have proposed the need for risk governance ${ }^{1}$ mechanisms that can be enacted far earlier in the nano-innovation process, reducing the time needed to acquire critical risk characterisation data (Lee and Jose 2008; Owen et al. 2009a). In some cases, the precautionary principle $^{2}$ has been invoked to support decisions in the absence of full scientific certainty. For instance, the Environment Agency in the UK recommended that unbound carbon nanotubes are treated as hazardous waste (Environment Agency 2008). Others, however, have concluded that, for the most part, there is still insufficient evidence to invoke the precautionary principle (Aitken et al. 2009; Stebbing 2009), and, hence, this issue may quite possibly take many years to resolve.

\section{Current and near-future research effort distributions}

In order to gauge whether current NM risk research efforts are responding to the challenges outlined above, we have undertaken a snapshot review of research efforts, mainly in terms of peer-reviewed journal publications, research projects and public funding within the fields of traditional risk assessment paradigms, complementary tools to risk assessment and risk governance mechanisms as they apply to NM. This is not intended to be a complete analysis of research publications and projects within the field of environment, health and safety aspects (EHS) of NM (see e.g. Aguar and Murcia Nicolás 2008;

\footnotetext{
${ }^{1}$ Defined according to Renn (2008): "Risk governance includes the totality of actors, rules, conventions, processes and mechanisms concerned with how relevant risk information is collected, analysed and communicated, and how management decisions are taken".

2 As described by the European Commission (2000).
} 
SCENIHR 2009 for more complete overviews); instead, we aim to provide a synopsis of the general direction and distribution of efforts to date.

We searched peer-reviewed journal articles within different nano-risk-related fields using the ISI Web of Knowledge article database (http://apps.isiknowledge. com) and the International Council on Nanotechnology (ICON) database ('quick' and 'advanced' searches, http://icon.rice.edu/research.cfm) which specifically focuses on EHS issues of NM. In addition, the OECD research project database (http://webnet.oecd.org/ NanoMaterials/Pagelet/Front/Default.aspx?) which also specifically focuses on projects within health and environmental safety of NM was also searched. These databases were accessed and used on 30 June 2009. See Fig. 1 for more details on the search methodology, including search terms used.

In terms of the number of published research articles and research projects within different nano-risk fields, the majority $(60.1 \%)$ of these research efforts were within the topics of 'toxicity, 'ecotoxicity' and 'exposure' of NM (Fig. 1). There were also relatively high numbers of research articles found in topics of 'management' and 'monitoring' of nanotechnology, -material or -particle using the ISI Web of Knowledge, although the number of articles found within these topics is significantly less when using the ICON database which specifically focuses on EHS aspects of NM. In comparison, only 6.8 and $1.6 \%$ of research efforts were in the areas of 'risk governance' and 'decision making', respectively.

Similar patterns are also seen in the distribution of research projects completed or underway within NM EHS issues. According to the OECD project database for health and environmental safety research of $\mathrm{NM}$, there were 153 projects listed under topics of 'exposure' and 99 projects within 'toxicity' or 'ecotoxicity', compared to 45 within 'risk assessment', 37 within 'monitoring', 16 within 'management' and 6 within 'risk management'. Only two projects are within the field of 'risk governance' and three in the field of 'decision making' (Fig. 1).

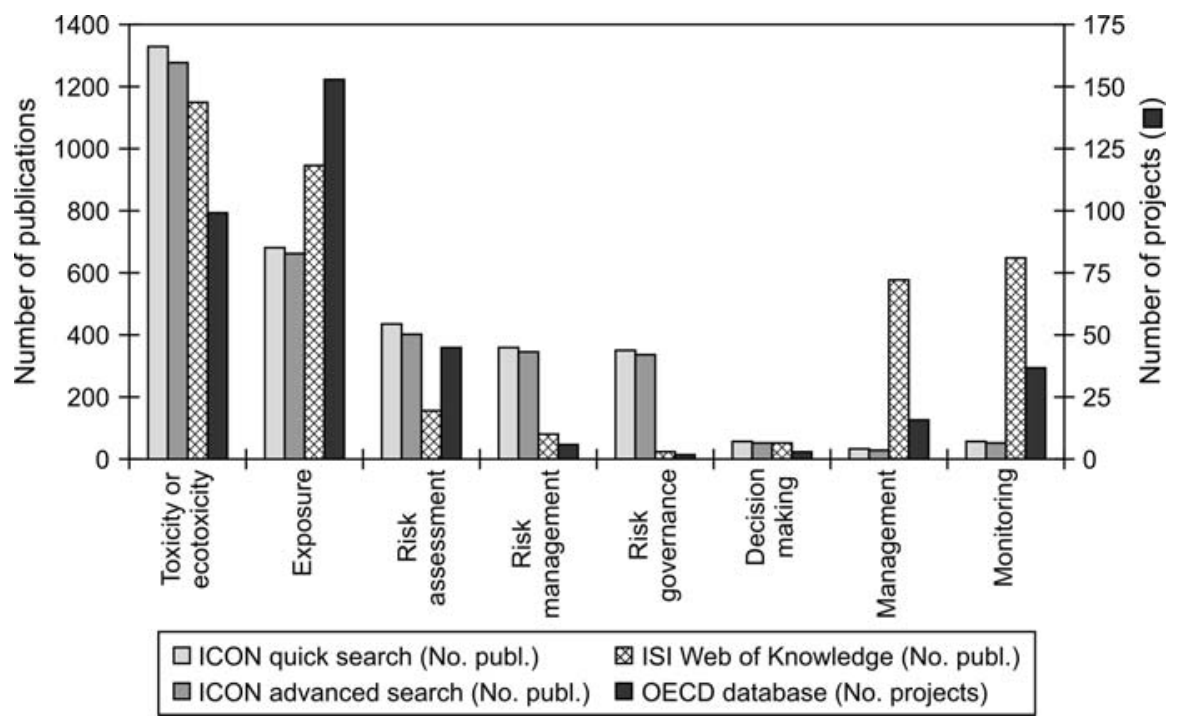

Fig. 1 Comparison of number of journal article publications and research projects within different nano-risk topics and environment, health and safety (EHS) issues of nanomaterials (NM). The ISI Web of Knowledge (http://apps.isiknowledge. com) and ICON Virtual Journal (http://icon.rice.edu/research. $\mathrm{cfm}$ ) which specifically focuses on EHS issues of NM (using both 'quick' and 'advanced' search options) were used to search for scientific journal publications. The OECD NM risk research project database (http://webnet.oecd.org/Nano Materials/Pagelet/Front/Default.aspx?) was used to search for completed or on-going research projects, shown on the secondary axis. Searches were made within all years in these databases, and were accessed and used on 30 June 2009. The following search terms were used within the 'topic' fields of the database search engines: 'toxicity', 'ecotoxicity', 'exposure', 'risk assessment', 'risk management', 'risk governance', 'decision making', 'management' and 'monitoring'. Since the ISI Web of Knowledge database is not confined to NM risk research, as in the case of the ICON and OECD databases, the previously cited search terms were used together with 'nanotechnology', 'nanomaterial' or 'nanoparticle' 
It is evident, not unsurprisingly, that much of the ongoing research fits within a chemical-based risk assessment paradigm. Very little research is directly addressing the key issues of near-term decision support highlighted above and by others (RCEP 2008; Brown 2009; Linkov et al. 2009b).

Furthermore, this situation is not likely to change in the near future. Of the nearly 200 projects funded either through the EU Framework Programmes (totally $€ 32$ million), EU Member States, Candidate Countries or Countries associated to Sixth Framework Programme (FP6) or Seventh Framework Programme (FP7) (totally $€ 47$ million), only a few projects focus on risk governance or decision making (Aguar and Murcia Nicolás 2008). The great majority of projects have been dedicated towards improving technical knowledge or developing new test protocols and equipment. Similar patterns are seen in US public funding schemes through the National Nanotechnology Initiative (NNI 2008a, b). Funding schemes outlined by the EU's current FP7 programme do not appear to deviate much from previous research priorities (Aguar and Murcia Nicolás 2008; European Commission 2009). The recent FP7 call, (Theme 4 Nanosciences, Nanotechnologies, Materials and New Production Technologies-NMP), published 29 July 2009 , is aimed largely at gaining more technical knowledge for risk assessment (European Commission 2009). Very few references are made on improved

Box 1 In response to the challenges of potential health and environmental risk assessments of nanomaterials (NM) and making decisions regarding these potential risks, as highlighted governance or decision making of nanotechnologies, with no specific calls within these areas. These are largely subsumed within wider goals, such as improved social acceptance, sustainable development and the development of reference materials. This is not surprising given the overarching strategy outlined by the EU nanotechnologies action plan (European Commission 2005) which is yet to acknowledge the key issues raised in this article and by others (e.g. RCEP 2008).

\section{Redressing the imbalance: a path forward and recommendations}

This analysis has shown that despite the recognized serious challenges that NM present for fulfilling traditional chemical-based risk assessment frameworks and the time this will likely take, the large majority of decision support research is directed to fit ultimately within this framework. Decision makers, therefore, may not be well equipped to make decisions concerning NM under conditions of extensive uncertainty in relation to environmental and human health protection in the near term. It is clear, in our view, that there is a need for a program of research and knowledge transfer specifically aimed at supporting near- and medium-term decision making, in real time and at the same pace as nano-innovation

in this analysis, we propose some key areas for future research to ensure the responsible emergence of nanotechnologies

\begin{tabular}{|c|c|c|}
\hline Recommendation & Rationale & Implementation \\
\hline $\begin{array}{l}\text { Adaptive and more } \\
\text { responsive risk } \\
\text { governance frameworks }\end{array}$ & $\begin{array}{l}\text { Rapid nanotechnologies innovation } \\
\text { out-paces regulatory governance based } \\
\text { on traditional risk assessment } \\
\text { Lengthy, post-innovation risk } \\
\text { investigations }\end{array}$ & $\begin{array}{l}\text { Encourage and support research on risk governance } \\
\text { which specifically focuses on timely yet informed } \\
\text { decision making in light of uncertainty and rapid } \\
\text { nano-innovation } \\
\text { Integrate responsible innovation early (upstream) } \\
\text { in innovation process }\end{array}$ \\
\hline $\begin{array}{l}\text { Alternative, complementary } \\
\text { tools to risk assessment }\end{array}$ & $\begin{array}{l}\text { Early approximate risk evaluations } \\
\text { Relative comparison of NM risks for } \\
\text { decision support }\end{array}$ & $\begin{array}{l}\text { Immediate, rigorous testing of already-developed } \\
\text { tools to fully evaluate their functionality and } \\
\text { limitations } \\
\text { Continue development of new tools including those } \\
\text { which may complement risk assessment }\end{array}$ \\
\hline $\begin{array}{l}\text { Health and environmental } \\
\text { surveillance }\end{array}$ & $\begin{array}{l}\text { Early warning system } \\
\text { Potential safety net }\end{array}$ & $\begin{array}{l}\text { Use of biomonitoring, such as: } \\
\text { Filter-feeders in aquatic 'hot spots' } \\
\text { Monitor health of occupational workers } \\
\text { Direct Toxicity Assessment of effluents }\end{array}$ \\
\hline
\end{tabular}


itself (Guston and Sarewitz 2002), see Box 1. Furthermore, since there are already a number of $\mathrm{NM}$ on the market with varying degrees of potential for exposure (Limbach et al. 2008; RCEP 2008; SCENIHR 2009), we also recommend the use of environment and health surveillance as an early warning system to act as a safety net around such a decision support program, to which it may also serve to inform (Box 1). We have highlighted these areas that might be worthy of consideration in such a research program in Box 1 and provide further justification for these in the following section.

Adaptive and more responsive risk governance frameworks

If the development of regulation based on quantitative risk assessment is an inherently slow governance process, then one answer might be to undertake research that leads to one or more governance frameworks that are more responsive and adaptive. This is a view that has been articulated by a number of authors, including RCEP (2008), Brown (2009) and Owen et al. (2009a). There is a foundation for this study, including a number of alternative risk governance frameworks that have been proposed in recent years, such as those suggested by the International Risk Governance Council (IRGC 2007), Environmental Defense and Dupont (Nano Risk Framework, Environmental Defense and Dupont 2007) and SMARTEN (Strategic Management and Assessment of Risks and Toxicity of Engineered Nanomaterials) (Metcalfe et al. 2009). These typically not only combine some of the traditional parameters of risk assessment (hazard identification, exposure assessment, etc.) and risk management (in the case of the Nano Risk Framework), but may also incorporate wider aspects (e.g. social, economic and cultural aspects, expert analysis).

Others have proposed broader governance models for decision making of nanotechnology. For example, real-time technology assessment attempts to integrate nano-science and innovation with social science and policy at early stages of research and development rather than dealing with decision-making issues after innovation has already taken a place in society (Guston and Sarewitz 2002). This has the potential to prevent lengthy post-NM production debates by addressing key issues early in the innovation process, given that the inclusive steps involved are coordinated and well guided to minimize delay in the process. While real-time technology assessment mainly aims to assist decision-making processes by incorporating other (societal) factors, it is not yet clear if more timely decisions will ultimately be aided by this process.

Others have specifically recognised the key issue of driving governance 'upstream' in the nano-innovation process. For example, the European Commission's Code of Conduct for Nanosciences and Nanotechnologies Research was established in 2007 (European Commission 2008a), providing guidance to steer the responsible development of nanotechnology at an early stage. This includes specific recommendations aimed towards enhancing communication of the risks, benefits and uncertainties in addition to the development of scientific tools and knowledge, albeit described, in general, rather than in specific terms.

In short, while there are a number of potential avenues to pursue, a comprehensive programme of research in this area is currently lacking. Therefore, we recommend the continued development of research on risk governance frameworks that specifically aims to strengthen the timeliness of decision making processes in the face of rapid nanotechnologies innovation.

Alternative, complementary tools to risk assessment

In addition to the risk governance frameworks and approaches described above, a wide variety of tools have either been developed or deployed for approximate risk evaluations or decision making about (some) NM risks using available information. These include the Precautionary Matrix to identify potentially dangerous applications within production (Höck et al. 2008) and a categorisation framework to identify different exposure potentials based on the location of the nano-structured material in a product (Hansen et al. 2008). Multi-Criteria Decision Analysis (MCDA) and SMAA-TRI models have also been proposed, which compare and rank alternatives in NM risk decision making (Linkov et al. 2007; Tervonen et al. 2009). Furthermore, expert elicitation has been put forth to help compensate for large data gaps (Morgan 2005), as well as adaptive management to help create flexible and iterative processes (Davis 
2007; Linkov et al. 2007). In general, these tools attempt to provide either an early attempt to approximate or compare some NM risks for decision support, even if it is, for example ranking the risks of different nanoparticles.

While these tools and models may be valuable in many aspects, especially in terms of 'thinking outside the box' in regard to early estimates and comparisons of NM risks and better decision-making strategies, one main limitation is that many (if not most) of these tools and models have not been thoroughly 'tested' and applied to many NM, and, therefore, their robustness and applicability is not yet clear. Therefore, we recommend that the developed frameworks and tools, some of which have been described here, be immediately and rigorously tested to fully evaluate their functionality and limitations. This should be complementary to the continued development and amendment of alternative governance frameworks and tools.

The need for surveillance

Since decisions under uncertainty and especially ignorance will always be prone to varying degrees of error, some have suggested the need for 'corrigibility' (Collingridge 1980). In other words, under uncertain circumstances, it is important to ensure that such decisions can be reversed at minimum cost (economic or otherwise). Hence, environmental and health surveillance may have the potential to serve as an important safety net or early warning system (Owen et al. 2009b; Saunders and Mohammed 2009; Schulte et al. 2009) to any decision support system for NM risks, whether based on prospective risk assessment or an alternate framework. In particular, the use of biomonitoring may be particularly useful given the difficulties in detecting and measuring nanoparticles in complex environmental matrices (e.g. Hassellov et al. 2008). This might include evaluating the toxicity of NM-containing environmental discharges (e.g. 'whole effluent assessment' or 'direct toxicity assessment', Owen et al. 2009b) or the use of filter feeding organisms in aquatic environments where there is an anticipated high degree of exposure to NM (Baun et al. 2009). Biomonitoring may also encompass the monitoring and surveillance of occupational workers' health in the light of potentially hazardous effects of NM (Nasterlack et al. 2008). In fact, the National Institute of
Occupational Health and Safety (NIOSH) recently recommended hazard surveillance as a foundation to implement safety measures (NIOSH 2009), and the OECD has recommended the inclusion of health monitoring, surveillance and biological monitoring for occupational workers (OECD 2009c).

\section{Conclusions}

Although the traditional chemical-based risk assessment framework is a powerful approach, its use for estimating the health and environmental risks of NM in the near-term may be limited due to the time and costs needed to generate meaningful results. This is due to the extensive risk uncertainties and complex types and numbers of NM encountered in current production. The fast-paced development of NM and nanoproducts is only compounding this problem. Given these limitations, decision makers may not currently be well equipped if decisions are to be based mainly upon results generated from quantitative risk assessment. We see this as the central issue for the responsible emergence of nanotechnologies.

Despite the above, research efforts thus far have been mainly put towards acquiring knowledge that will most likely be fed into chemical-based risk assessment procedures. These efforts include a predominance of research publications and projects within the fields of (eco)toxicology and human and environmental exposure of NM, while research in broader issues such as decision making and risk governance are comparatively minimal. Research supporting quantitative risk characterization of NM is indeed important, and we do not advocate abandonment of this at any cost. However, as scientists and policy makers, we must face the reality that knowledge gaps are not expected to be closed in the near future and may take decades to close in many cases. In order to ensure the protection of the environment and human health, this suggests the need for a research programme as significant as that which feeds into quantitative risk assessment and which addresses the fundamental issue of timely, yet, informed decision making regarding potential NM risks. Although a few alternative risk frameworks have been proposed, it is not clear whether they will address this key concern. Furthermore, although some complementary governance approaches and 
decision support tools have been suggested, their comprehensive evaluation and development has yet to be undertaken.

In conclusion, we suggest the need for an international research programme that specifically addresses critical issues of risk governance and timely decision making as these relate to NM specifically, and emerging technologies more generally. This programme might include research into more efficient and anticipatory risk governance mechanisms as well as a systematic evaluation of available complementary tools to risk assessment and, where necessary, further tools under development. Finally, the development of environmental and health surveillance is needed to act as a safety net and an early warning system while these issues are being addressed. We recommend that active research within these areas should be among the essential steps taken in the near future to ensure the responsible emergence of nanotechnologies, and ultimately the protection of human and environmental health.

\section{References}

Aguar P, Murcia Nicolás JJ (2008) EU nanotechnology R\&D in the field of health and environmental impact of nanoparticles. European Commission, January 28. ftp://ftp. cordis.europa.eu/pub/nanotechnology/docs/final-version. pdf

Aitken R, Hankin S, Ross B, Tran CL, Stone V, Fernandes TF, Donaldson K, Duffin R, Chaudhry Q, Wilkins TA, Wilkins SA, Levy LS, Rocks SA, Maynard A (2009) EMERGNANO: a review of completed and near completed environmental, health and safety research on nanomaterials and nanotechnology. UK Department for Environment, Food and Rural Affairs (DEFRA), March. http://randd.defra. gov.uk/Document.aspx?Document=CB0409_7910_FRP. pdf

Baun A, Hansen SF (2008) Environmental challenges for nanomedicine. Nanomedicine 3:605-608

Baun A, Hartmann N, Grieger K, Hansen SF (2009) Setting the limits for engineered nanoparticles in European surface waters. J Environ Monit 11:1774-1781

Brown S (2009) The new deficit model. Nat Nanotechnol 4:609-611

Choi J, Ramachandran G, Kandlikar M (2009) The impact of toxicity testing costs on nanomaterial regulation. Environ Sci Technol 43:3030-3034

Collingridge D (1980) The social control of technology. Frances Pinter, London

Crane M, Handy R, Garrod J, Owen R (2008) Ecotoxicity test methods and environmental hazard assessment for engineered nanoparticles. Ecotoxicology 17:421-437
Davis JM (2007) How to assess the risks of nanotechnology: learning from past experience. J Nanosci Nanotechnol 7:402-409

DEFRA (2006) Characterising the potential risks posed by engineered nanoparticles. Department for Environment, Food and Rural Affairs. http://www.defra.gov.uk/ environment/nanotech/research/pdf/nanoparticlesprogress report.pdf

DEFRA (2007) Characterising the potential risks posed by engineered nanoparticles-second UK government research report. Department for Environment, Food and Rural Affairs. http://www.defra.gov.uk/environment/ nanotech/research/pdf/nanoparticles-riskreport07.pdf

Elder A, Lynch I, Grieger K, Chan-Remillard S, Gatti A, Gnewuch H, Kenawy E, Korenstein R, Kuhlbusch T, Linker F, Matias S, Monteiro-Riviere NA, Pinto VR, Rudnitsky R, Savolainen A, Shvedova A (2009) Human health risks of engineered nanomaterials: critical knowledge gaps in nanomaterials risk assessment. In: Linkov I, Steevens JA (eds) Nanomaterials: risks and benefits. Springer, Dordrecht, pp 3-30

Environment Agency (2008) Interim advice on wastes containing unbound carbon nanotubes. http://www.nerc.ac. uk/research/programmes/nanoscience/events/documents/ nano-waste.pdf

Environmental Defense, DuPont (2007) Nano Risk Framework. http://www.environmentaldefense.org/documents/6496_ Nano\%20Risk\%20Framework.pdf

EPA (2009) Nanomaterial research strategy. Environmental Protection Agency. http://www.epa.gov/nanoscience/files/ nanotech_research_strategy_final.pdf

European Commission (2000) Communication from the commission on the precautionary principle. http://ec.europa. eu/dgs/health_consumer/library/pub/pub07_en.pdf

European Commission (2003) Technical guidance document on risk assessment-part I. http://ecb.jrc.ec.europa.eu/ Documents/TECHNICAL_GUIDANCE_DOCUMENT/ EDITION_2/tgdpart1_2ed.pdf

European Commission (2005) Nanosciences and nanotechnologies: an action plan for Europe 2005-2009. ftp://ftp. cordis.europa.eu/pub/nanotechnology/docs/action_plan_ brochure.pdf

European Commission (2008a) Commission recommendation of 07/02/2008 on a code of conduct for responsible nanosciences and nanotechnologies research. http://ec.europa. eu/nanotechnology/pdf/nanocode-rec_pe0894c_en.pdf

European Commission (2008b) Follow-up to the 6th meeting of the REACH competent authorities for the implementation of regulation (EC) 1907/2006 (REACH), 15-16 December 2008. http://ec.europa.eu/environment/chemicals/reach/ pdf/nanomaterials.pdf

European Commission (2009) Work programme 2010 cooperation theme 4, nanosciences, nanotechnologies, materials and new production technologies-NMP. http://cordis. europa.eu/fp $7 / \mathrm{dc} /$ index.cfm?fuseaction=UserSite.FP7 DetailsCallPage\&call_id=258\#infopack

European Food Safety Authority (2009) Scientific opinion: the potential risks arising from nanoscience and nanotechnologies on food and feed safety. http://www.efsa.europa. eu/EFSA/Scientific_Opinion/sc_op_ej958_nano_en.pdf? ssbinary $=$ true 
Grieger K, Hansen SF, Baun A (2009) The known unknowns of nanomaterials: describing and characterizing uncertainty within environmental, health and safety risks. Nanotoxicology 3:1-12

Guston DH, Sarewitz D (2002) Real-time technology assessment. Technol Soc 24:93-109

Handy RD, Owen R, Valsami-Jones E (2008) The ecotoxicology of nanoparticles and nanomaterials: current status, knowledge gaps, challenges, and future needs. Ecotoxicology 17:315-325

Hansen SF (2009) Regulation and risk assessment of nanomaterials: too little, too late? $\mathrm{PhD}$ thesis, Technical University of Denmark

Hansen SF, Michelson ES, Kamper A, Borling P, Stuer Lauridsen F, Baun A (2008) Categorization framework to aid exposure assessment of nanomaterials in consumer products. Ecotoxicology 17:438-447

Hanssen L, Walhout B, van Est R (2008) Ten lessons for a nanodialogue: the Dutch debate about nanotechnology thus far. Rathenau Institute. http://www.rathenauinstituut. com/downloadfile.asp?ID=1486

Hassellov M, Readman JW, Ranville JF, Tiede K (2008) Nanoparticle analysis and characterization methodologies in environmental risk assessment of engineered nanoparticles. Ecotoxicology 17:344-361

Höck J, Hofmann H, Krug H, Lorenz C, Limbach L, Nowack B, Riediker M, Schischke K, Som C, Stark W, Studer C, von Götz N, Wengert S, Wick P (2008) Guidelines on the Precautionary Matrix for synthetic nanomaterials. Federal Office for Public Health and Federal Office for the Environment. http://www.bag.admin.ch/themen/chemikalien/ 00228/00510/05626/index.html?lang=en\&download=M3 wBPgDB/8ull6Du36WenojQ1NTTjaXZnqWfVp3Uhmfh napmmc7Zi6rZnqCkkId3fH2DbKbXrZ6lhuDZz8mMps $2 \mathrm{gpKfo}$

ICON (2008) Towards predicting nano-biointeractions: an international assessment of nanotechnology environment, health and safety research needs. International Council on Nanotechnology, May 1. http://cohesion.rice.edu/Centers AndInst/ICON/emplibrary/ICON_RNA_Report_Exec_ Summ2.pdf

IRGC (2007) Nanotechnology risk governance: recommendations for a global, coordinated approach to the governance of potential risks. International Risk Governance Council http://www.irgc.org/IMG/pdf/PB_nanoFINAL2_2_.pdf

ISO (2008a) International workshop on documentary standards for measurement and characterization in nanotechnologies, NIST, Gaithersburg, Maryland, USA 26-28 February 2008. International Organization for Standardization, June. http://www.standardsinfo.net/info/livelink/ fetch/2000/148478/7746082/assets/final_report.pdf

ISO (2008b) Spécification technique internationale nanotechnologies - terminology and definitions for nano-objectsnanoparticle, nanofibre and nanoplate. International Organization for Standardization. http://www.iso.org/ iso/iso_catalogue/catalogue_tc/catalogue_detail.htm?cs number $=44278$

Lee R, Jose PD (2008) Self-interest, self-restraint and corporate responsibility for nanotechnologies: emerging dilemmas for modern managers. Technol Anal Strateg Manag 20:113-126
Limbach LK, Bereiter R, Müller E, Krebs R, Gälli R, Stark WJ (2008) Removal of oxide nanoparticles in a model wastewater treatment plant: influence of agglomeration and surfactants on clearing efficiency. Environ Sci Technol 42:5828-5833

Linkov I, Satterstrom FK, Steevens J, Ferguson E, Pleus RC (2007) Multi-criteria decision analysis and environmental risk assessment for nanomaterials. J Nanopart Res 9: 543-554

Linkov I, Steevens J, Adlakha-Hutcheon G, Bennett E, Chappell M, Colvin V, Davis JM, Davis T, Elder A, Hansen SF, Hakkinen PB, Hussain SM, Karkan D, Korenstein R, Lynch I, Metcalfe C, Ramadan AB, Satterstrom FK (2009a) Emerging methods and tools for environmental risk assessment, decision-making, and policy for nanomaterials: summary of NATO advanced research workshop. J Nanopart Res 11:513-527

Linkov I, Satterstrom FK, Monica JC, Hansen SF, Davis T (2009b) Nano risk governance: current developments and future perspectives. Nanotechnol Law Bus 6:203-220

Mantovani E, Porcari A, Meili C, Widmer M (2009) Mapping study on regulation and governance of nanotechnologies. FramingNano, January. http://www.framingnano.eu/ima ges/stories/FramingNanoMappingStudyFinal.pdf

Maynard AD, Aitken RJ, Butz T, Colvin V, Donaldson K, Oberdorster G, Philbert MA, Ryan J, Seaton A, Stone V, Tinkle SS, Tran L, Walker NJ, Warheit DB (2006) Safe handling of nanotechnology. Nature 444:267-269

Metcalfe C, Bennett E, Chappell MA, Steevens JA, Depledge M, Goss G, Goudey S, Kaczmar S, O'Brien N, Picado A (2009) SMARTEN: strategic management and assessment of risks and toxicity of engineered nanomaterials. In: Linkov I, Steevens JA (eds) Nanomaterials: risks and benefits. Springer, Dordrecht, pp 95-109

Morgan K (2005) Development of a preliminary framework for informing the risk analysis and risk management of nanoparticles. Risk Anal 25:1621-1635

Nasterlack M, Zober A, Oberlinner C (2008) Considerations on occupational medical surveillance in employees handling nanoparticles. Int Arch Occup Environ Health 81:721-726

NIOSH (2009) Approaches to safe nanotechnology: managing the health and safety concerns associated with engineered nanomaterials. National Institute for Occupational Safety and Health, March. http://www.cdc.gov/niosh/docs/2009$125 /$

NNI (2008a) FY budget \& highlights. National Nanotechnology Initiative. http://www.nano.gov/NNI_FY09_budget_ summary.pdf

NNI (2008b) Strategy for nanotechnology-related environmental, health and safety research. National Nanotechnology Initiative, February. http://www.nano.gov/NNI_ EHS_Research_Strategy.pdf

OECD (2008a) Current developments/activities on the safety of manufactured nanomaterials: Tour de table at the 4th meeting of the working party on manufactured nanomaterials, 11-13 June 2008. Organisation for Economic Co-operation and Development. http://www.olis.oecd.org/ olis/2008doc.nsf/linkto/envjm-mono(2008)29

OECD (2008b) List of manufactured nanomaterials and list of endpoints for phase one of the OECD testing programme. Organisation for Economic Co-operation and 
Development, July 7. http://www.olis.oecd.org/olis/2008 doc.nsf/LinkTo/NT000034C6/\$FILE/JT03248749.PDF

OECD (2009a) Endocrine disrupter testing and assessment. Organisation for Economic Co-operation and Development. http://www.oecd.org/document/62/0,2340,en_ 2649_34377_2348606_1_1_1_1,00.html

OECD (2009b) OECD guidance document for the diagnosis of endocrine-related histopathology of fish gonads. Organisation for Economic Co-operation and Development, January 7. http://www.oecd.org/dataoecd/33/27/42140701.pdf

OECD (2009c) Preliminary analysis of exposure measurement and exposure mitigation in occupational settings: manufactured nanomaterials. Organisation for Economic Cooperation and Development, April 17. http://www.oecd. org/dataoecd/36/36/42594202.pdf

OECD (2009d) Safety of manufactured nanomaterials. Organisation for Economic Co-operation and Development. http://www.oecd.org/department/0,3355,en_2649_37015 404_1_1_1_1_1,00.html

OECD (2009e) Preliminary review of OECD test guidelines for their applicability to manufactured nanomaterials. Organisation for Economic Co-operation and Development, July 10. http://www.olis.oecd.org/olis/2009doc.nsf/Link To/NT000049AE/\$FILE/JT03267900.PDF

Owen R, Handy R (2007) Formulating the problems for environmental risk assessment of nanomaterials. Environ Sci Technol 41:5582-5588

Owen R, Baxter D, Maynard T, Depledge M (2009a) Beyond regulation: risk pricing and responsible innovation. Environ Sci Technol. doi:10.1021/es803332u

Owen R, Crane M, Grieger K, Handy R, Linkov I, Depledge M (2009b) Strategic approach for the management of environmental risk uncertainties posed by nanomaterials. In: Linkov I, Steevens JA (eds) Nanomaterials: risks and benefits. Springer, Dordrecht, pp 369-384

Powell MC, Griffin MP, Tai S (2008) Bottom-up risk regulation? How nanotechnology risk knowledge gaps challenge federal and state environmental agencies. Environ Manag 42:426-443

Project on Emerging Nanotechnologies (2008) An inventory of nanotechnology-based consumer products currently on the market. Woodrow Wilson International Center for Scholars. http://www.nanotechproject.org/inventories/ consumer/. Accessed 30 June 2009

RCEP (2008) Novel materials in the environment: the case of nanotechnology. Royal Commission on Environmental Pollution, November. http://www.officialdocuments.gov. uk/document/cm74/7468/7468.pdf
Renn O (2008) Risk governance: coping with uncertainty in a complex world. Earthscan, London

Rocks S, Pollard S, Dorey R, Levy L, Harrison P, Handy R (2008) Comparison of risk assessment approaches for manufactured nanomaterials. Department for environment, food and rural affairs, May 30. http://randd.defra. gov.uk/Document.aspx?Document=CB0403_7306_ABS. doc

Saunders P, Mohammed M (2009) Environmental public health tracking: piloting methods for surveillance of environmentally related diseases in England and Wales. Environ Geochem Health 31:309-313

SCENIHR (2007) The appropriateness of the risk assessment methodology in accordance with the Technical Guidance Documents for new and existing substances for assessing the risks of nanomaterials. European Commission, Scientific Committee on Emerging and Newly Identified Health Risks, June 21-22. http://ec.europa.eu/health/ph_ risk/committees/04_scenihr/docs/scenihr_o_010.pdf

SCENIHR (2009) Risk assessment of products of nanotechnologies. European Commission, Scientific committee on emerging and newly identified health risks, January 19. http://ec.europa.eu/health/ph_risk/committees/04_scenihr/ docs/scenihr_o_023.pdf

Schulte P, Geraci C, Schubauer-Berigan M, Zumwalde R, Mayweather C, McKernan J (2009) Issues in the development of epidemiologic studies of workers exposed to engineered nanoparticles. J Occup Environ Med 51: 323-335

Shatkin JA (2008) Informing environmental decision making by combining life cycle assessment and risk analysis. J Ind Ecol 12:278-281

Stebbing M (2009) Avoiding the trust deficit: public engagement, values, the precautionary principle and the future of nanotechnology. J Bioeth Inq 6:37-48

Sumpter JP, Johnson AC (2008) 10th anniversary perspective: Reflections on endocrine disruption in the aquatic environment: from known knowns to unknown unknowns (and many things in between). J Environ Monit 10:1476-1485

Tervonen T, Linkov I, Figueira JR, Steevens J, Chappell M, Merad M (2009) Risk-based classification system of nanomaterials. J Nanopart Res 11:757-766

Wiesner MR, Lowry GV, Jones KL, Hochella MF, Di Giulio RT, Casman E, Bernhardt E (2009) Decreasing uncertainties in assessing environmental exposure, risk, and ecological implications of nanomaterials. Environ Sci Technol. doi:10.1021/es803621k 